\title{
Contact Dermatitis to Biperiden and Photocontact Dermatitis to Phenothiazines in a Pharmacist
}

\author{
WAKIO TORINUKI \\ Division of Dermatology, Tohoku Kosei-Nenkin Hospital, \\ Sendai 983
}

Torinuki, W. Contact Dermatitis to Biperiden and Photocontact Dermatitis to Phenothiazines in a Pharmacist. Tohoku J. Exp. Med., 1995, 176 (4), 249-252 - A case of contact dermatitis to biperiden, an anti-Parkinson agent, and photocontact dermatitis to phenothiazines in a pharmacist was reported. The patient developed eczematous lesions on exposed area after she had worked at a psychiatric hospital for 6 months. She showed positive patch test reaction to biperiden. In addition, she reacted positively to photopatch testing with ultraviolet $\mathrm{A}$ and phenothiazines such as chlorpromazine and perphenazine. To our knowledge, contact dermatitis to biperiden has not been previously reported in the English literature. - biperiden; contact dermatitis; phenothiazines; photocontact dermatitis

The recent and common drugs capable of causing photosensitivity reactions include new quinolone antibiotics, non-steroidal anti-inflammatory drugs, anticancer drugs and so on. On the other hand, the number of patients with photoallergic contact dermatitis to halogenated salicylanilides and phenothiazines gradually decreased. A case of contact dermatitis to biperiden, an anti-Parkinson agent, and photocontact dermatitis to phenothiazines (chlorpromazine and perphenazine) in a pharmacist is reported.

\section{Patient and Methods}

\section{Patient}

A 47-year-old female was referred to our dermatologic clinic in August 1993 with an eruption on exposed areas. She had been making up prescriptions for a few hours per day as a pharmacist at a psychiatric hospital from September 1992. The eruption developed on March 1993. There was no history of systemic illness prior to the present illness. Physical examination revealed papular erythematous lesions over the light exposed areas affecting the face, neck, ears, forearms and the dorsa of the hands. She was diagnosed as having contact or photocontact dermatitis. The lesions cleared after systemic and topical steroid therapy. 
About 4 weeks after resolving of the lesions, patch and photopatch tests were carried out.

\section{Light source}

Fourteen fluorescent tubes (Toshiba FL32S-BL; Toshiba, Tokyo) emitting mainly ultraviolet A (UVA) peaking at $352 \mathrm{~nm}$ and 7 tubes (Toshiba FL20SE30) emitting mainly ultraviolet B (UVB) peaking at $305 \mathrm{~nm}$ were used, housed in two reflector units of a Dermaray (Model M-DMR-100; Clinical Supply Co., Tokyo). The irradiation of UVA and UVB, which were measured with a Topcon UV radiometer UVR-305/365 (Clinical Supply), were 6.5 and $1.0 \mathrm{~mW} / \mathrm{cm}^{2}$, respectively, at a distance of $30 \mathrm{~cm}$.

\section{Phototesting}

Screening phototests were performed on the upper-back of the patient, being evaluated 1 day later. The minimal erythema dose for UVB was within normal limits. The patient developed no abnormal reaction to UVA up to $8 \mathrm{Joule} / \mathrm{cm}^{2}$.

\section{Patch and photopatch testing}

The patient and the four control subjects were tested with 29 materials that the patient had always handled for medical prescriptions. The materials were applied in duplicate under occlusion on symmetric areas of the back. After $24 \mathrm{hr}$, both the rows of materials were uncovered, and the first evaluation was performed. One of the rows was then irradiated with $8 \mathrm{Joule} / \mathrm{cm}^{2}$ of UVA, and the tests were evaluated again 1 and 2 days later, according to International Contact Dermatitis Research Group guidelines. Photopatch testing with UVB or visible light was not performed.

\section{Results and Discussion}

The results of patch and photopatch testing are summarized in Table 1. Patch test with biperiden was weakly positive $(+)$. Weakly positive photopatch tests $(+)$ were obtained with both chlorpromazine and perphenazine, although the patch test results were negative $(-)$. The patient also had doubtful reactions $(+?)$ of photopatch test to pantothine, phenobarbital, propericiazine, sucralfate and thioridazine. On the other hand, four normal controls showed no reactions to patch and photopatch testing with all the materials. The data indicate that the patient had both contact dermatitis to biperiden and photocontact dermatitis to phenothiazines.

Although the number of patients with photocontact dermatitis to phenothiazines gradually decreased, there have been some case reports in Japan, even recently (Kodama et al. 1990; Hamanaka et al. 1991). On the other hand, reports on contact dermatitis to biperiden was not found in the English literature, based on retrieval frou CD-ROM MEDLINE ${ }^{\circledR}$ on Silver Platter. 
TABLE 1. Results of patch and photopatch testing with UVA at 2 days after irradiation

\begin{tabular}{|c|c|c|c|}
\hline No. & Materials (concentration, $\%$ in petrolatum) & Patch test & $\begin{array}{c}\text { Photopatch test } \\
\text { (UVA, } 8 \text { Joule } / \mathrm{cm}^{2} \text { ) }\end{array}$ \\
\hline 1 & $\operatorname{Aminoxan}^{\circledR} \quad(1)$ & - & - \\
\hline 2 & Bifidobacterium (1) & - & - \\
\hline 3 & Biperiden (1) & + & + \\
\hline 4 & Bromperidol (1) & - & - \\
\hline 5 & Chlorpromazine $(0.01)$ & - & + \\
\hline 6 & Codeine Phosphate (1) & - & - \\
\hline 7 & Diazepam (1) & - & - \\
\hline 8 & Finalin G (1) & - & - \\
\hline 9 & Gamma Oryzanol (1) & - & - \\
\hline 10 & Haloperidol (1) & - & - \\
\hline 11 & Levomepromazine (1) & - & - \\
\hline 12 & Moperone (1) & - & - \\
\hline 13 & Pantothine (1) & - & + ? \\
\hline 14 & Perphenazine $(0.01)$ & - & + \\
\hline 15 & Pipamperone (1) & - & - \\
\hline 16 & Phenytoin (1) & - & - \\
\hline 17 & Phenobarbital (1) & - & $+?$ \\
\hline 18 & Primidone (1) & - & - \\
\hline 19 & Promethazine (1) & - & - \\
\hline 20 & Propericiazine (1) & - & $+?$ \\
\hline 21 & Scopolia extract (1) & - & - \\
\hline 22 & Sibneet-S ${ }^{\circledR}$ & - & - \\
\hline 23 & Sodium valproate (1) & - & - \\
\hline 24 & Sucralfate (1) & - & $+?$ \\
\hline 25 & Sulpiride (1) & - & - \\
\hline 26 & Teprenone (1) & - & - \\
\hline 27 & Thioridazine (1) & - & $+?$ \\
\hline 28 & Tiotixene (1) & - & - \\
\hline 29 & Ubidecarenone (1) & - & - \\
\hline
\end{tabular}
- , negative; + ?, doubtful reaction; + , weakly positive.

This patient might have been sensitized during handling drugs for medical prescriptions. Pharmacists should use rubber gloves, when dispensing the medication, to prevent contact or photocontact allergy. 


\section{References}

1) Hamanaka, H., Nakamura, Y., Taniguchi, Y. \& Shimizu, M. (1991) A case of photocontact dermatitis due to chlorpromazine. Hifu, 33, Suppl. 10, 142-147. (in Japanese with English abstract)

2) Kodama, A., Adachi, A., Shimizu, R. \& Ichihashi, M. (1990) A case of persistent light reactor due to chlorpromazine. Hifu, 32, Suppl. 8, 242-247. (in Japanese with English abstract) 